\title{
Ab Initio Quantum Chemical Studies of Six-Center Bond Exchange Reactions Among Halogen and Halogen Halide Molecules
}

\author{
I. Noorbatcha ${ }^{1}$, B. Arifin ${ }^{2}$, and S.M. Zain ${ }^{3}$ \\ ${ }^{1}$ Department of Biotechnology Engineering, Faculty of Engineering, International Islamic \\ University, Jalan Gombak, 53100 Kuala Lumpur, Malaysia \\ ibrahiman@iiu.edu.my \\ ${ }^{2}$ Faculty of Science, University Technology MARA, 40450 Shah Alam, Malaysia \\ ${ }^{3}$ Department of Chemistry, University Malaya, 50603 Kuala Lumpur, Malaysia
}

\begin{abstract}
The possibility of six-center bond exchange reaction among halogen and halogen halide molecules is confirmed using ab initio quantum chemical methods. The following reactions: $\left(\mathrm{Cl}_{2}\right)_{2}+\mathrm{Br}_{2} \rightarrow 2 \mathrm{BrCl}+\mathrm{Cl}_{2} ;\left(\mathrm{Cl}_{2}\right)_{2}+\mathrm{HI}$ $\rightarrow \mathrm{HCl}+\mathrm{ICl}+\mathrm{Cl}_{2}$ and $(\mathrm{HI})_{2}+\mathrm{F}_{2} \rightarrow \mathrm{HF}+\mathrm{HI}+\mathrm{IF}$ were studied. The energy barrier for these reaction were found to be very low $(<7 \mathrm{kcal} \mathrm{mol})$. These results are consistent with the molecular beam results.
\end{abstract}

Keywords: Ab initio, six-center bond exchange reaction, halogen, halogen halide.

\section{Introduction}

There are only a few reaction mechanisms, which postulate termolecular reaction among three diatomic molecules [1]. However, there is no termolecular reaction available for which we have both experimental and theoretical evidence [2-5]. A definitive experimental evidence for a termolecular reaction through a six centered transition state [TS] during the bond exchange among halogen molecules is available from molecular beam experiments. Dixon and Herschbach [6] found that the following reactions:

$$
\begin{aligned}
& \left(\mathrm{Cl}_{2}\right)_{2}+\mathrm{Br}_{2} \rightarrow 2 \mathrm{BrCl}+\mathrm{Cl}_{2} \\
& \left(\mathrm{Cl}_{2}\right)_{2}+\mathrm{HI} \rightarrow \mathrm{HCl}+\mathrm{ICl}+\mathrm{Cl}_{2}
\end{aligned}
$$

could proceed at collision energies as low as $3 \mathrm{kcal} \mathrm{mol}^{-1}$. A similar reaction,

$$
(\mathrm{HI})_{2}+\mathrm{F}_{2} \rightarrow \mathrm{HF}+\mathrm{HI}+\mathrm{IF}
$$

has been observed by Durana and McDonald [7]. However, no theoretical calculations are available in support of these experiments. It would be interesting to know if the theoretical calculations can support the above experimental findings involving halogens and hydrogen halides. In the present work we have carried out ab initio quantum 
mechanical calculations for the existence of the six-center TS for the reactions R1-R3, and find that our calculations confirms the presence of six centered TS for these reactions.

Table 1. Calculated Energy barrier and vibration frequency of the transitions states

\begin{tabular}{|c|c|c|}
\hline Method & $\begin{array}{c}\mathrm{E}_{\mathrm{b}} \\
(\mathrm{kcal} / \mathrm{mol})\end{array}$ & $v\left(\mathrm{~cm}^{-1}\right)$ \\
\hline \multicolumn{3}{|c|}{$\mathrm{Cl}_{4} \mathrm{Br}_{2}$} \\
\hline $\mathrm{HF} / 6-311 \mathrm{G}^{*}$ & 93.80 & $546.80 \mathrm{i}$ \\
\hline HF/MIDI! & 76.91 & $664.30 \mathrm{i}$ \\
\hline $\mathrm{HF} / \mathrm{cc}-\mathrm{pVDZ}$ & 87.44 & $613.01 \mathrm{i}$ \\
\hline HF/cc-pVTZ & 92.42 & $522.32 \mathrm{i}$ \\
\hline MP2/MIDI! & 32.86 & $249.52 \mathrm{i}$ \\
\hline MP2/cc-pVDZ & 42.10 & $272.83 \mathrm{i}$ \\
\hline B3LYP/6-311G* & 27.95 & $277.24 \mathrm{i}$ \\
\hline B3LYP/MIDI! & 5.70 & $235.79 \mathrm{i}$ \\
\hline B3PW91/MIDI! & 7.30 & $238.19 \mathrm{i}$ \\
\hline BHandH/MIDI! & 7.11 & $368.50 \mathrm{i}$ \\
\hline B3LYP/cc-pVDZ & 25.31 & $268.20 \mathrm{i}$ \\
\hline B3LYP/cc-pVTZ & 30.34 & $285.16 \mathrm{i}$ \\
\hline \multicolumn{3}{|c|}{$\mathrm{Cl}_{4} \mathrm{HI}$} \\
\hline $\mathrm{HF} / 6-311 \mathrm{G}^{* *}$ & 76.30 & $314.13 \mathrm{i}$ \\
\hline HF/MIDI! & 72.85 & $689.83 \mathrm{i}$ \\
\hline HF/cc-pVTZ & 75.87 & $261.90 \mathrm{i}$ \\
\hline HF/cc-pVQZ & 74.49 & $224.35 \mathrm{i}$ \\
\hline HF/LANL2DZ & 56.0 & $70.33 \mathrm{i}$ \\
\hline MP2/MIDI! & 32.98 & $851.98 \mathrm{i}$ \\
\hline MP2/cc-pVTZ & 30.18 & $555.36 \mathrm{i}$ \\
\hline B3LYP/6-311G** & 21.99 & $427.86 \mathrm{i}$ \\
\hline B3LYP/MIDI! & 4.85 & $359.71 \mathrm{i}$ \\
\hline B3PW91/MIDI! & 6.20 & $361.72 \mathrm{i}$ \\
\hline BHandH/MIDI! & 7.05 & $657.03 \mathrm{i}$ \\
\hline B3LYP/cc-pVTZ & 26.11 & $471.34 \mathrm{i}$ \\
\hline B3LYP/cc-pVQZ & 26.50 & $438.63 \mathrm{i}$ \\
\hline B3LYP/LANL2DZ & 5.73 & $71.65 \mathrm{i}$ \\
\hline \multicolumn{3}{|c|}{$\mathrm{H}_{2} \mathrm{I}_{2} \mathrm{~F}_{2}$} \\
\hline $\mathrm{HF} / 6-311 \mathrm{G}^{* *}$ & 54.35 & $1035.00 \mathrm{i}$ \\
\hline HF/MIDI! & 55.75 & $1766.82 \mathrm{i}$ \\
\hline HF/cc-pVTZ & 57.17 & $643.65 \mathrm{i}$ \\
\hline HF/cc-pVQZ & 54.91 & $628.78 \mathrm{i}$ \\
\hline HF/LANL2DZ & 48.28 & $1483.38 \mathrm{i}$ \\
\hline MP2/MIDI! & 8.55 & $227.75 \mathrm{i}$ \\
\hline MP2/cc-pVTZ & 3.79 & $416.40 \mathrm{i}$ \\
\hline B3LYP/MIDI! & -3.21 & $274.79 \mathrm{i}$ \\
\hline B3PW91/MIDI! & -0.38 & $205.41 \mathrm{i}$ \\
\hline BHandH/MIDI! & -0.37 & $684.24 \mathrm{i}$ \\
\hline B3LYP/cc-pVTZ & -1.24 & $44.34 \mathrm{i}$ \\
\hline B3LYP/LANL2DZ & -5.49 & $47.08 \mathrm{i}$ \\
\hline
\end{tabular}



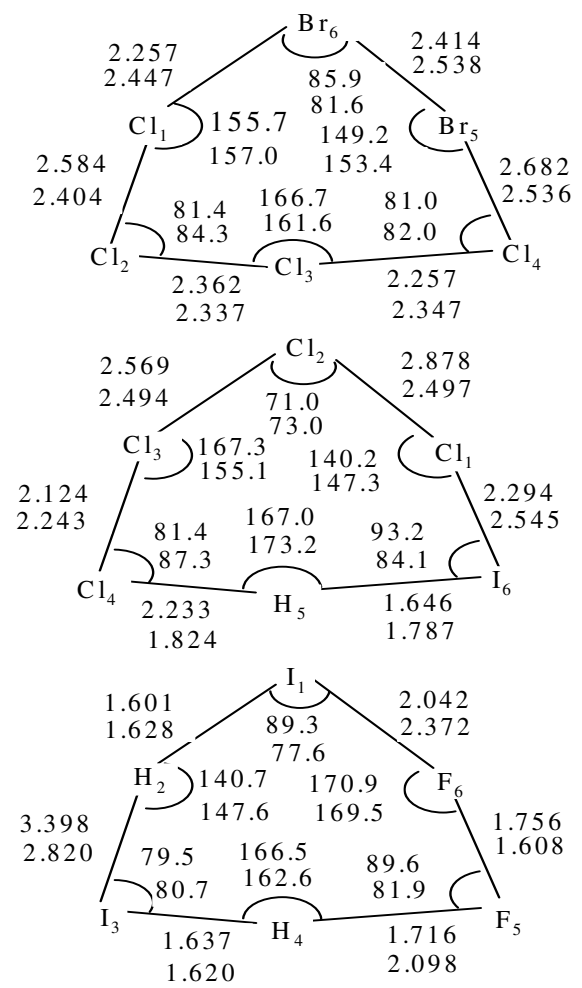

Fig. 1. Transition state geometries for R1 (top), R2 (middle) and R3 (bottom). The upper entries in each geometry was obtained using HF/cc-pVTZ and the lower entries were obtained using B3LYP/cc-pTVZ. The bond lengths are in $\AA$ and the angles in degrees.

\section{Results and Discussion}

All electronic structure calculations were done using the Gaussian 98 [8]. Geometries for the TS were optimized at the Hartree-Fock (HF) level of theory using 6-311G*, MIDI!, cc-pVDZ, cc-pVTZ, cc-pVQZ (for $\mathrm{H}, \mathrm{Cl}$ and Br), SDB-cc-pVTZ, SDB-ccpVQZ (for I only) and LANL2DZ basis sets [9-10]. The second order Moller-Plesset perturbation theory (MP2) methods and density functional theory (DFT) methods, B3LYP, B3PW91 and BHandH [10] were also used to optimize the geometries using the above basis sets. The TS were verified by checking for the presence of only one imaginary frequency $(v)$ and by performing intrinsic reaction coordinate (IRC) calculations. The energy barrier $\left(\mathrm{E}_{\mathrm{b}}\right)$ for the reactions was obtained after zero point energy corrections.

The calculated $E_{b}$ and $v$ values are listed in Table 1. The HF energy barriers are found to be much higher than the MP2 and DFT energy barriers emphasizing the significance of the correlation energy in cyclic systems. The MIDI! basis set gives lower $\mathrm{E}_{\mathrm{b}}$ values compared to the $6-311 \mathrm{G}^{*}$ basis set for both the HF and DFT methods. It is significant to note that all the DFT methods predicts low barrier heights in the 
range of 5-7 kcal/mol for $\mathrm{R} 1$ and $\mathrm{R} 2$ which is in good agreement with the experimental results. However, for R3 the DFT methods yield negative $\mathrm{E}_{\mathrm{b}}$ values. These negative values could be due to tendency of the DFT methods to underestimate the energy barriers or due to the numerical errors associated with the absence of pruned grids for iodine atoms in DFT methods as implemented in Gaussian 98. These negative values may not be due to relativistic effects, as the use of relativistically corrected LANL2DZ basis set also leads to negative $E_{b}$ values. The flatness of the potential energy surface around the transition state region also makes it difficult to detect it accurately. Under this scenario, it can be safely assumed that R3 has near-zero energy barrier.

The TS structures obtained using HF/cc-pVTZ and B3LYP/cc-pVTZ methods are given in Figure 1. All the TS geometries were found to be planar. The TS geometries look more like a bulging triangle, rather than as a hexagon as expected for six centered reactions, with the heavier atom at the corner of the triangle and the lighter atom at the middle of the bulging sides of the triangle.

\section{Conclusion}

The present ab initio calculations clearly confirms the possibility of six-centered exchange reactions: $\left(\mathrm{Cl}_{2}\right)_{2}+\mathrm{Br}_{2} \rightarrow 2 \mathrm{BrCl}+\mathrm{Cl}_{2} ;\left(\mathrm{Cl}_{2}\right)_{2}+\mathrm{HI} \rightarrow \mathrm{HCl}+\mathrm{ICl}+$ $\mathrm{Cl}_{2}$ and $(\mathrm{HI})_{2}+\mathrm{F}_{2} \rightarrow \mathrm{HF}+\mathrm{HI}+\mathrm{IF}$ with low activation barriers. These results are in agreement with the molecular beam experimental results.

Supporting information Available: Energies and geometries of TS for all the methods.

\section{References}

1. Laidler, K.J.: Chemical Kinetics; Mc-Graw Hill, New York (1965)

2. Rabinowitz, M.J.; Gardiner, W.C.: Chem. Phys. Lett. 124 (1986) 63-67

3. (a) Wright, J.S. Can. J. Chem. 53 (1975) 549-555 (b) Wright, J.S. Chem. Phys. Lett. 6 (1970) 476-481

4. (a) Dixon, D.A.; Stevens, R.M.; Herschbach, D.A.: Faraday Discuss. Chem. Soc. 62 (1977) 110-126 (bb) Heidrich D.; Van Eikema Hommes, N.J.R., Schleyer, P .V. R.: J. Comput. Chem. 14 (1993) 1149-1153 (c) Janoschek, R.; Kalcher, J.: Int. J. Quant. Chem. 38 (1990) 653-664

5. NoorBatcha, I.; Thareja, S.; Sathyamurthy, N. J.: Phys. Chem. 91 (1987) 2171-2173

6. (a) Dixon, D.A.; Herschbach, D.R.: J. Am. Chem. Soc. 97 (1975) 6268-6270 (b) Dixon, D.A. Herschbach, D.R. Ber. Bunsenges.: Phys. Chem. 145 (1977) 145-151

7. Durana, J.F.; McDonald, J.D.: J. Am. Chem. Soc. 98 (1976) 1289-1291

8. Gaussian 98, Revision A.7,. Frisch, M. J.; et. al.: Gaussian, Inc., Pittsburgh PA(1998)

9. http://www.emsl.pnl.gov:2080

10. Gaussian 98 User's Reference, Gaussian, Inc., Pittsburgh PA(1998) 